\title{
Lower heart rate in the early postoperative period does not correlate with long-term outcomes after repair of type A acute aortic dissection
}

\author{
Tetsu Ohnuma $\cdot$ Naoyuki Kimura $\cdot$ Yusuke Sasabuchi $\cdot$ Kayo Asaka \\ Junji Shiotsuka · Tetsuya Komuro · Hideyuki Mouri · Alan T. Lefor • \\ Hideo Adachi • Masamitsu Sanui
}

Received: 23 September 2013/Accepted: 7 February 2014/Published online: 25 February 2014

(C) The Author(s) 2014. This article is published with open access at Springerlink.com

\begin{abstract}
Little evidence exists regarding the need for a reduction in postoperative heart rate after repair of type A acute aortic dissection. This single-center retrospective study was conducted to determine if lower heart rate during the early postoperative phase is associated with improved long-term outcomes after surgery for patients with type A acute aortic dissection. We reviewed 434 patients who underwent aortic repair between 1990 and 2011. Based on the average heart rate on postoperative days $1,3,5$, and 7 , 434 patients were divided into four groups, less than 70 , $70-79,80-89$, and greater than 90 beats per minute. The mean age was $63.3 \pm 12.1$ years. During a median followup of 52 months (range 16-102), 10-year survival in all groups was $67 \%$, and the 10 -year aortic event-free rate was $79 \%$. The probability of survival and being aortic event-free using Kaplan-Meier estimates reveal that there is no significant difference when stratified by heart rate. Cox proportional regression analysis for 10 -year mortality shows that significant predictors of mortality are age [Hazard Ratio (HR) 1.04; $95 \%$ confidence interval (CI) $1.07-1.06 ; p=0.001]$ and perioperative stroke (HR 2.30;
\end{abstract}

T. Ohnuma (囚) · Y. Sasabuchi · K. Asaka · J. Shiotsuka ·

T. Komuro $\cdot$ H. Mouri $\cdot$ M. Sanui

Department of Anesthesiology and Critical Care Medicine,

Saitama Medical Center, Jichi Medical University,

1-847 Amanuma-cho, Omiya-ku, Saitama-shi,

Saitama 330-8503, Japan

e-mail: tetsu.fe3@gmail.com; tetsuohnuma@gmail.com

N. Kimura $\cdot$ H. Adachi

Department of Cardiovascular Surgery, Saitama Medical Center, Jichi Medical University, Saitama, Japan

A. T. Lefor

Department of Surgery, Jichi Medical University, Shimotsuke, Japan
$95 \%$ CI $1.18-4.50 ; p=0.024)$. Neither stratified heart rate around the time of surgery nor beta-blocker use at the time of discharge was significant. There is no association between stratified heart rate in the perioperative period with long-term outcomes after repair of type A acute aortic dissection. These findings need clarification with further clinical trials.

Keywords Aortic dissection - Heart rate $\cdot$ Outcomes . Surgery

\section{Introduction}

Acute aortic dissection (AAD) is a lethal cardiovascular disease. Despite continuing improvements in surgical and medical management, the 10-year survival rate in patients with type A AAD has remained low at 53.4-67.7 \% [1-5]. Medical therapy to reduce blood pressure (BP) and heart rate in patients with $\mathrm{AAD}$ is widely used. Among medications, treatment with beta-blockers is reported as the key medical therapy by lowering both BP and cardiac contractility [6-8]. Heart rate is simply used as a surrogate of the degree of antiadrenergic and anti-inotropic effect of the drug therapy. Only one study has evaluated the efficacy of tight heart rate control in patients with type B AAD, which showed that the probability of aortic event-free survival was significantly higher in the tight heart rate control group compared with the conventionally managed heart rate group [8]. However, little evidence exists regarding the need for a reduction in postoperative heart rate after repair of type A AAD.

We conducted this study to evaluate whether a lower heart rate during the early postoperative phase improves the long-term outcomes after surgical repair of type A AAD. 


\section{Materials and methods}

Study population

We retrospectively reviewed 434 patients who underwent surgical repair of a type A AAD at Jichi Medical University Saitama Medical Center between 1990 and 2011. Operations were performed urgently in all patients within 14 days of the onset of symptoms. The ethics committee approved this study, and the requirement for informed consent was waived. Patients who died within 6 days after surgery or had missing data, were excluded. Aortic dissection was proven by enhanced computed tomography, and defined as according to the Stanford and DeBakey classifications. We used data from the first operation during the hospitalization if more than one operation was performed. Preoperative variables evaluated in this study include age, gender, smoking, past medical history (hypertension, diabetes, dyslipidemia, chronic obstructive pulmonary disease, myocardial infarction, cardiac operation and bicuspid aortic valve), hypotension, aortic regurgitation, surgical parameters (duration of cardiopulmonary bypass, aortic cross clamp time, use of deep-hypothermic circulatory arrest), and laboratory data (hemoglobin and serum creatinine level). Postoperative events and outcomes include: the need for reoperation, aortic rupture in the hospital, atrial fibrillation, renal replacement therapy, stroke, prolonged ventilation (defined as the requirement ventilation for more than $48 \mathrm{~h}$ ), tracheostomy, ICU length of stay, hospital length of stay and in-hospital mortality.

\section{Medical management and long-term follow-up}

Intravenous beta-blockers and/or calcium channel blockers were administered to reduce systolic $\mathrm{BP}<120 \mathrm{mmHg}$ as initial therapy in the ICU after surgical repair. Intravenous medications were replaced by oral antihypertensive drugs including calcium channel blockers, beta-blockers, angiotensin-converting enzyme inhibitors, angiotensin receptor blockers and diuretics, as appropriate. The decision to give oral antihypertensive medications was at the discretion of the treating physician.

Heart rate and BP at 6 a.m., 2 p.m., and 8 p.m. daily during the hospitalization were recorded. Based on the average heart rate on postoperative days $1,3,5$, and 7, 434 patients were divided into four groups, $\mathrm{A}:<70$ beats per minute (bpm), B: 70-79 bpm, C: $80-89 \mathrm{bpm}$, and D: $>90 \mathrm{bpm}$.

Follow-up data including survival time and cause of death once in every 3 years after repair of type A AAD were obtained by mailing a questionnaire to all patients. If responses were not returned, we contacted the patient, the patient's family or the family physician by telephone.
Aortic events were defined as aortic rupture, secondary operation, endovascular stenting, late organ ischemia or sudden death [8].

Statistical analysis

Data are presented as mean \pm standard deviation, medians (interquartile ranges, IQR) or percentages, as appropriate. Either Chi-square or Fisher's exact test was used for nominal variables, and one-way analysis of variance was used to compare continuous variables. The Kruskal-Wallis test was used for nonparametric variables. A $p$ value of $<0.05$ was considered statistically significant. Cox proportional hazard analysis was conducted to identify independent risk factors for 10-year mortality and aortic events. Cumulative 10-year survival rate and aortic event-free rate stratified by heart rate were analyzed with Kaplan-Meier analysis using the Log-rank test. All analysis was performed using SPSS 19.0 (IBM, USA).

\section{Results}

Four hundred and seventy patients underwent surgical repair of type A AAD. Twenty-six patients died within 6 days and data of 10 patients were missing, as shown in

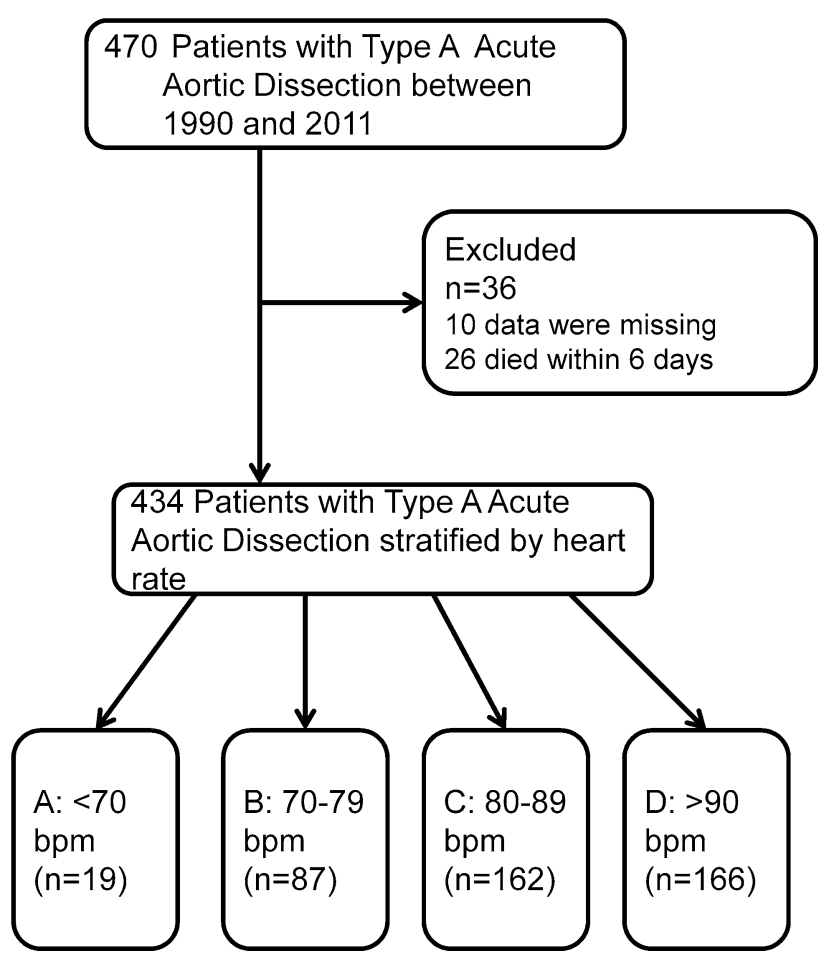

Fig. 1 Patients included in the study, and the schema for classification into study Groups A, B, C and D, stratified by heart rate (bpmbeats per minute) 
Table 1 Baseline

characteristics of patients with type A acute aortic dissection categorized by heart rate $(n=434)$
$C O P D$ chronic obstructive pulmonary disease, $A R$ aortic regurgitation

\begin{tabular}{|c|c|c|c|c|c|}
\hline \multirow[t]{2}{*}{ Variable } & \multicolumn{5}{|c|}{ Heart rate (bpm) } \\
\hline & $<70$ & $70-79$ & $80-89$ & $>90$ & $p$ value \\
\hline Patient number & 19 & 87 & 162 & 166 & \\
\hline \multicolumn{6}{|l|}{ Characteristics } \\
\hline Male $(\%)$ & 52.6 & 48.3 & 51.9 & 51.2 & 0.96 \\
\hline Age (years) & $65 \pm 10$ & $64 \pm 10$ & $63 \pm 13$ & $63 \pm 13$ & 0.93 \\
\hline Smoking (\%) & 47.4 & 49.4 & 48.1 & 45.2 & 0.91 \\
\hline \multicolumn{6}{|l|}{ Medical history } \\
\hline Hypertension (\%) & 89.5 & 75.9 & 67.9 & 66.9 & 0.11 \\
\hline Diabetes (\%) & 5.3 & 3.4 & 4.9 & 7.8 & 0.51 \\
\hline Dyslipidemia (\%) & 15.8 & 32.2 & 11.7 & 16.3 & 0.001 \\
\hline COPD (\%) & 0 & 1.1 & 2.5 & 4.8 & 0.41 \\
\hline Previous myocardial infarction (\%) & 10.5 & 4.6 & 3.7 & 4.8 & 0.61 \\
\hline Previous cardiac operation (\%) & 0 & 1.1 & 1.9 & 1.2 & 0.91 \\
\hline Marfan syndrome (\%) & 0 & 1.1 & 3.1 & 3.0 & 0.87 \\
\hline Bicuspid aortic valve (\%) & 0 & 2.3 & 0.6 & 0.6 & 0.45 \\
\hline \multicolumn{6}{|l|}{ Preoperative laboratory data } \\
\hline Serum creatinine $(\mathrm{mg} / \mathrm{dl})$ & $1.9 \pm 2.8$ & $1.2 \pm 1.4$ & $1.0 \pm 0.6$ & $1.0 \pm 0.8$ & 0.002 \\
\hline Hemoglobin (g/dl) & $12.4 \pm 2.0$ & $12.1 \pm 1.8$ & $12.3 \pm 2.0$ & $12.3 \pm 1.9$ & 0.75 \\
\hline Preoperative shock (\%) & 15.8 & 26.4 & 33.3 & 27.7 & 0.36 \\
\hline Preoperative AR (\%) & 10.5 & 11.5 & 9.9 & 15.1 & 0.56 \\
\hline \multicolumn{6}{|l|}{ DeBakey classification } \\
\hline Type I (\%) & 73.7 & 63.2 & 58.6 & 68.1 & 0.26 \\
\hline Type II (\%) & 5.3 & 11.5 & 16.7 & 7.2 & 0.05 \\
\hline Type IIIb retrograde $(\%)$ & 21.1 & 23.0 & 24.1 & 24.7 & 0.98 \\
\hline
\end{tabular}

patients $(20 \%)$ in Group B (70-79 bpm), 162 patients (37\%) in Group C (80-89 bpm), and 166 patients (38\%) in Group D ( $>90 \mathrm{bpm})$. No patient had an average heart rate less than $60 \mathrm{bpm}$. Postoperative average systolic and diastolic BP were $121 \pm 10,69 \pm 7 \mathrm{mmHg}$, respectively. Tables 1 and 2 showed baseline and perioperative details categorized by the heart rate group. Significant differences between the four groups were seen in regard to dyslipidemia, preoperative serum creatinine, operative time, reexploration for bleeding, atrial fibrillation, need for renal replacement therapy, prolonged ventilation, and postoperative average diastolic BP. ICU length of stay and hospital length of stay were also significantly different among the groups by univariate analysis.

The postoperative medications are shown in Table 3. Most patients in the study (91\%) required at least one antihypertensive medication at the time of discharge, which included beta-blockers (54\%), angiotensin-converting enzyme inhibitors $(11 \%)$, angiotensin receptor blockers $(32 \%)$, calcium channel blockers $(62 \%)$, and diuretics $(28 \%)$. Beta-blocker use was significantly associated with a lower heart rate $(p<0.001)$.

Cumulative survival rate from the time of admission in all groups was $97 \%$ at 1 month, $93 \%$ at 1 year, $81 \%$ at 5 years, and $67 \%$ at 10 years. Cumulative aortic event- 
Table 2 Intraoperative and postoperative details and shortterm outcomes of patients with type A acute aortic dissection categorized by heart rate
$C P B$ cardiopulmonary bypass, DHCA deep-hypothermic circulatory arrest, $C A B G$ coronary artery bypass graft, $S B P$ systolic blood pressure, $D B P$ diastolic blood pressure

\begin{tabular}{|c|c|c|c|c|c|}
\hline \multirow[t]{2}{*}{ Variable } & \multicolumn{5}{|c|}{ Heart rate (bpm) } \\
\hline & $<70$ & $70-79$ & $80-89$ & $>90$ & $p$ value \\
\hline \multicolumn{6}{|l|}{ Surgery characteristics } \\
\hline Operation time $(\min )$ & $351 \pm 125$ & $337 \pm 96$ & $363 \pm 114$ & $398 \pm 150$ & 0.003 \\
\hline CPB time (min) & $148 \pm 72$ & $142 \pm 45$ & $142 \pm 48$ & $151 \pm 59$ & 0.34 \\
\hline Aorta cross clamp time (min) & $106 \pm 50$ & $105 \pm 35$ & $101 \pm 34$ & $103 \pm 44$ & 0.89 \\
\hline DHCA time (min) & $35 \pm 20$ & $35 \pm 14$ & $35 \pm 14$ & $34 \pm 16$ & 0.99 \\
\hline Hemi-arch replacement (\%) & 26.3 & 31.0 & 22.8 & 17.5 & 0.10 \\
\hline Aortic arch replacement (\%) & 21.1 & 13.8 & 9.9 & 16.9 & 0.20 \\
\hline Aortic valve replacement (\%) & 5.3 & 0 & 1.2 & 1.2 & 0.29 \\
\hline Bentall (\%) & 0 & 3.4 & 4.9 & 3.6 & 0.89 \\
\hline CABG $(\%)$ & 0 & 6.9 & 4.9 & 9.6 & 0.29 \\
\hline Entry resection $(\%)$ & 78.9 & 75.9 & 72.8 & 71.5 & 0.83 \\
\hline Re-exploration for bleeding (\%) & 0 & 1.1 & 4.3 & 9.6 & 0.024 \\
\hline \multicolumn{6}{|l|}{ Postoperative events } \\
\hline Aortic rupture in hospital (\%) & 0 & 1.1 & 0.6 & 0.6 & 1.00 \\
\hline Atrial fibrillation (\%) & 15.8 & 29.9 & 34.0 & 46.7 & 0.005 \\
\hline Renal replacement therapy (\%) & 10.5 & 3.4 & 3.1 & 9.6 & 0.037 \\
\hline Perioperative stroke (\%) & 10.5 & 8.0 & 8.6 & 13.3 & 0.49 \\
\hline Prolonged ventilation (\%) & 47.4 & 32.6 & 33.8 & 50.0 & 0.008 \\
\hline Tracheostomy (\%) & 0 & 4.6 & 3.7 & 3.0 & 0.85 \\
\hline Postoperative average SBP (mmHg) & $118 \pm 9$ & $121 \pm 10$ & $121 \pm 11$ & $121 \pm 10$ & 0.54 \\
\hline Postoperative average DBP $(\mathrm{mmHg})$ & $65 \pm 8$ & $67 \pm 6$ & $69 \pm 7$ & $70 \pm 7$ & $<0.001$ \\
\hline \multicolumn{6}{|l|}{ Short-term outcomes } \\
\hline ICU stay (days) & $5(3-10)$ & $5(4-7)$ & $5(4-7)$ & $7(5-10)$ & $<0.001$ \\
\hline Hospital stay (days) & $20(15-31)$ & $20(16-28)$ & $23(18-30)$ & $25(19-35)$ & 0.005 \\
\hline Hospital mortality (\%) & 0 & 2.3 & 5.6 & 4.2 & 0.63 \\
\hline
\end{tabular}

Table 3 Postoperative medications

\begin{tabular}{lllllll}
\hline & \multicolumn{7}{l}{ Heart rate (bpm) } \\
\cline { 2 - 7 } Variable & Total & $<70$ & $70-79$ & $80-89$ & $>90$ & $p$ Value \\
\hline $\begin{array}{l}\text { Beta-blockers } \\
\begin{array}{l}\text { Initiation within } \\
7 \text { days after }\end{array}\end{array}$ & 52.1 & 73.7 & 70.6 & 58.2 & 32.7 & $<0.001$ \\
$\quad \begin{array}{l}\text { operation (\%) } \\
\text { At discharge (\%) }\end{array}$ & 53.8 & 68.4 & 68.2 & 59.5 & 39.0 & $<0.001$ \\
$\begin{array}{c}\text { ACE inhibitors at } \\
\text { discharge (\%) }\end{array}$ & 11.3 & 15.8 & 8.2 & 9.2 & 14.5 & 0.31 \\
$\begin{array}{c}\text { ARB at discharge } \\
(\%)\end{array}$ & 32.2 & 52.6 & 44.7 & 28.1 & 27.0 & 0.006 \\
$\begin{array}{c}\text { CCBs at discharge } \\
\begin{array}{c}\text { Diuretics at } \\
\text { discharge }\end{array}\end{array}$ & 62.5 & 78.9 & 68.2 & 58.8 & 61.0 & 0.23 \\
\hline
\end{tabular}

$A C E$ angiotensin-converting enzyme, $A R B$ angiotensin receptor blocker, $C C B$ calcium channel blocker

free rate in all groups was $98 \%$ at 1 month, $96 \%$ at 1 year, $91 \%$ at 5 years, and $79 \%$ at 10 years. The probability of 10-year survival categorized by heart rate using Kaplan-Meier analysis reveals no significant differences among the groups (A vs. B, $p=0.815$; A vs. C, $p=0.335$; A vs. $\mathrm{D}, p=0.415$ ), as shown in Fig. 2 . The probability of being 10-year aortic event-free was also not significantly different among the groups (A vs. B, $p=0.269$; A vs. C, $p=0.352$; A vs. D, $p=0.261$ ), as shown in Fig. 3. Cox proportional regression analysis for 10-year mortality showed that significant predictors of mortality include age [Hazard Ratio (HR) 1.04; $95 \%$ confidence interval (CI) 1.07-1.06; $p=0.001]$ and perioperative stroke (HR 2.30; $95 \%$ CI 1.18-4.50; $p=0.024$ ) (Table 4). Neither stratified heart rate nor beta-blocker use was significant. Cox proportional regression analysis for 10-year aortic events was also performed. Only a diagnosis of Marfan syndrome was a significant risk factor in that model (HR 6.59; $95 \%$ CI 2.57-16.87; $p<0.001$ ).

\section{Discussion}

In this study, we examined the association of heart rate, stratified into four groups, in the early postoperative period with long-term outcomes after repair of type A AAD. The key findings showed that there is no significant difference 


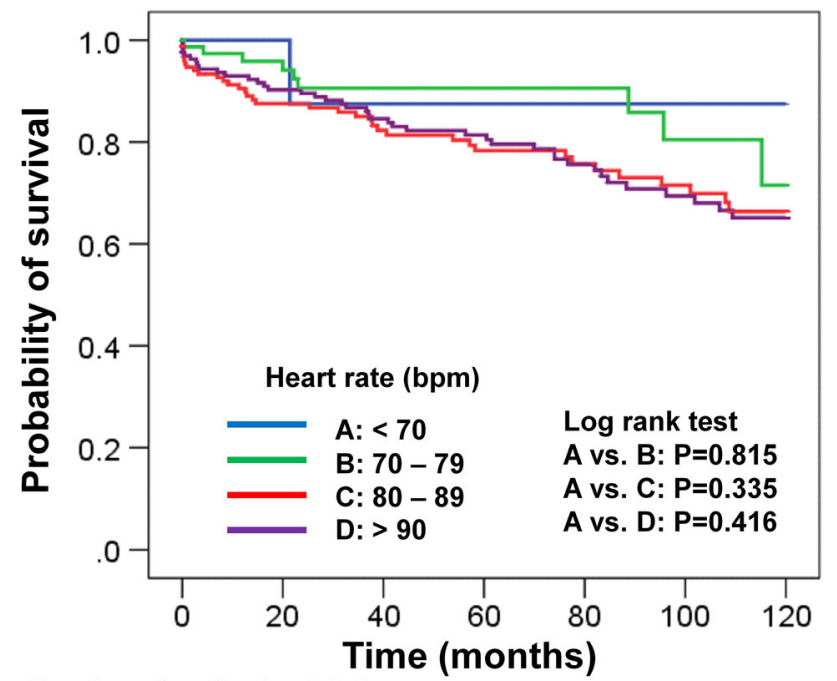

Number of patients at risk

$\begin{array}{lccccccc}\text { A: }<70 & 19 & 7 & 3 & 2 & 2 & 1 & 0 \\ \text { B: } 70-79 & 87 & 55 & 35 & 17 & 26 & 14 & 4 \\ \text { C: } 80-89 & 162 & 112 & 87 & 74 & 57 & 45 & 25 \\ \text { D: }>90 & 166 & 130 & 112 & 89 & 69 & 49 & 40\end{array}$

Fig. 2 Kaplan-Meier curves for overall 10-year survival in patients with type A acute aortic dissection, stratified by heart rate

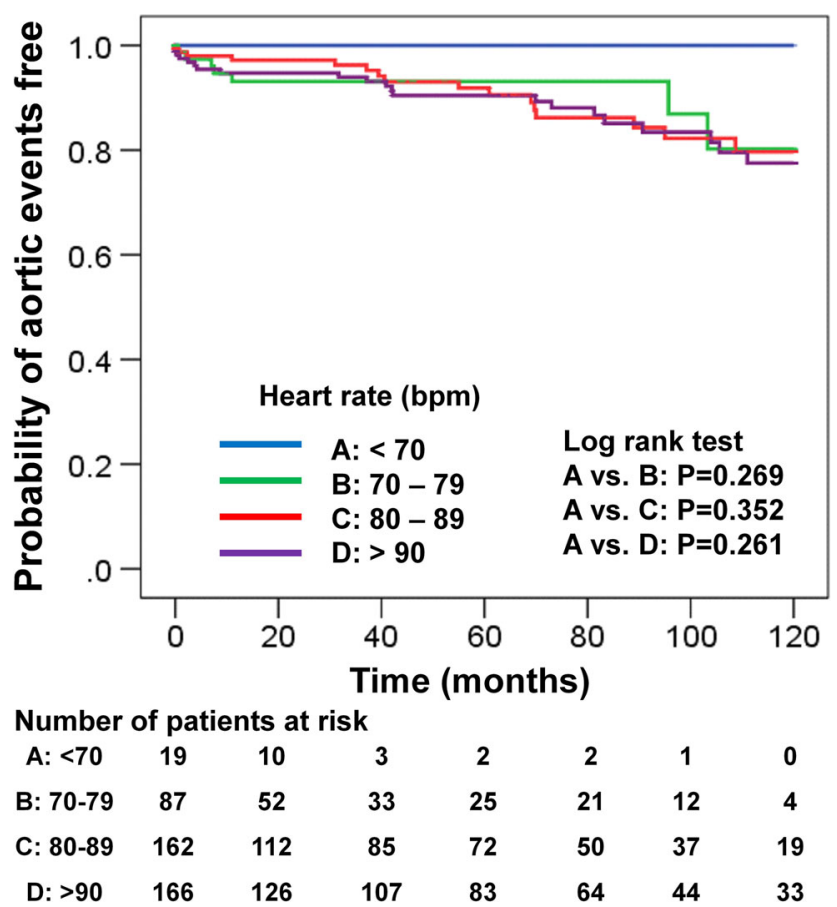

Fig. 3 Kaplan-Meier curves for 10-year aortic event-free survival in patients with type A acute aortic dissection, stratified by heart rate

in 10-year survival among the four groups using KaplanMeier analysis, nor is there a difference in the probability of being 10-year aortic event-free. Cox regression analysis showed that significant predictors of 10-year mortality
Table 4 Multivariate analysis of risk factors for 10-year mortality and aortic events

\begin{tabular}{lccc}
\hline Variable & $p$ value & Hazard ratio & $95 \% \mathrm{CI}$ \\
\hline 10-year mortality & & & \\
Age & 0.001 & 1.038 & $1.016-1.061$ \\
Perioperative stroke & 0.015 & 2.302 & $1.177-4.503$ \\
10-year aortic events & & & \\
Marfan syndrome & $<0.001$ & 6.591 & $2.574-16.872$ \\
\hline
\end{tabular}

CI confidence interval

include age and perioperative stroke. Only a diagnosis of Marfan syndrome was significant in the model for 10-year aortic events. Neither stratified heart rate nor any medication was a significant predictor for both 10 -year mortality and aortic events.

Patients with Type A AAD usually undergo surgical repair, and postoperative medical therapy is routinely given to stabilize the aortic wall and prevent aortic rupture and recurrent dissection [9]. Medical management of AAD was proposed in classic studies in the 1960s [10, 11]. In those studies, authors established two primary goals of medical therapy including reduction in BP and diminution of left ventricular ejection force (dp/dt). Among medications, beta-blockers have been a key drug for the control of both $\mathrm{dp} / \mathrm{dt}$ and BP by reducing both the heart rate and BP [12]. Reasonable targets for heart rate and systolic BP have been less than $60 \mathrm{bpm}$ and between 100 and $120 \mathrm{~mm} \mathrm{Hg}$, respectively [12]. Until the present, however, use of these medical therapies for AAD has not been supported by solid clinical evidence.

There is only one study that investigated the effect of tight heart rate control in patients with type B AAD [8]. Kodama and colleagues retrospectively collected 171 patients with type B AAD treated medically in a single center between 1997 and 2005. Based on the average heart rate at 3, 5, and 7 days after the onset, patients were divided into a tight heart rate management group $(<60 \mathrm{bpm}, n=32)$ and a control group ( $\geq 60 \mathrm{bpm}$, $n=139)$. The main outcome of Kaplan-Meier analysis for aortic event-free survival (median follow-up 27 months) showed that the tight heart rate control group had a significantly higher rate of being aortic event-free than the conventional heart rate control group $(p=0.017)$. In comparison, the current study did not show a significant difference in long-term outcomes when stratified by heart rate. While this discrepancy may be caused by physiologic differences between type A AAD and type B AAD, studies to date have not conclusively shown whether or not we need to further reduce the heart rate.

In patients who underwent repair of type A AAD, little was known about the effects of medical therapy on long- 
term survival $[13,14]$. In contrast, there have been several studies to evaluate the long-term outcomes of medical therapy in patients with type B AAD [7, 8, 13, 15-17]. Suzuki and colleagues [13] investigated the effects of medications on long-term outcomes in 1301 patients (722 with type A and 579 with type B) using the International Registry of Acute Aortic Dissection (IRAD) database from 1995 with follow-up to 5 years. The results of multivariate analysis of 654 surgically treated patients with type A AAD showed that beta-blocker use was significantly associated with lower mortality (HR $0.47,95 \%$ CI $0.25-0.90, p=0.02$ ). Calcium channel blockers and renin-angiotensin system inhibitors were not included in their model. There have been reports that calcium channel blockers' use is significantly associated with improved outcomes for patients with type B AAD [13, 16]. Regarding the present study, however, no other studies have shown a positive effect of long-term calcium channel blockers' use on patients with type A AAD. Although renin-angiotensin system inhibitors might be useful in patients with Marfan syndrome and aortic aneurysms [18, 19], no evidence exists regarding the effects of these medications on patients with Type A AAD.

As previously mentioned, BP control is the other primary goal of medical therapy in patients with type A AAD. A recent single-center study evaluated the impact of BP on 25-year outcomes following repair of type A AAD between 1984 and 2009 [3]. Based on the BP at late follow-up, all 252 patients were divided into three groups: systolic $\mathrm{BP}<120, \quad 120-140$, and $>140 \mathrm{mmHg}$. Patients who maintained a systolic $\mathrm{BP}<120 \mathrm{mmHg}$ had improved freedom from reoperation compared with those having a BP $120-140$ or $>140 \mathrm{mmHg}(p<0.001)$ by Kaplan-Meier analysis. The present study failed to show an association between postoperative systolic BP in the acute phase and, either 10-year mortality, or being aortic event-free, by Cox regression analysis. Although, we have not been able to investigate the effect of the late-phase $\mathrm{BP}$ in the type A $\mathrm{AAD}$ patients reviewed here, late follow-up of $\mathrm{BP}$ might be an important factor in addition to postoperative BP.

Marfan syndrome is one of the major inherited connective tissue disorders that may lead to the weakening of the aortic media, and subsequently to $\mathrm{AAD}$, aortic aneurysm or rupture. Previous clinical trials showed that Marfan syndrome was one of the risk factors for late aortic events $[20,21]$. In the current study, Marfan syndrome was included among the risk factors for the occurrence of longterm aortic events. This might be partially explained by the fact that the dissected aortic wall in patients with Marfan syndrome tends to develop aneurysmal dilatation due to wall weakness, more than in type A AAD patients [22].

There are several acknowledged limitations to this study. Most importantly, we evaluated only the acute phase of the average heart rate and $\mathrm{BP}$ on postoperative days $1,3,5$, and 7 , and we did not investigate the heart rate, BP or medications during long-term follow-up. Approximately, half of the patients after discharge are followed at regular hospital visits, and the remaining patients are followed in other hospitals or clinics. Thus, data for only about half of the patients regarding heart rate, $\mathrm{BP}$, and medications are available after discharge from the hospital. The protective factor of heart rate and BP is likely cumulative over time. The time points during the acute postoperative period may not be adequate surrogates for long-term control of heart rate, because the long-term heart rate and BP are probably different compared to those in the immediate postoperative period. These parameters may contribute to the failure to show a long-term difference in survival. Secondly, the present study is a single-center retrospective study. Although the sample size is not small compared with previous studies reporting long-term outcomes in patients with type A AAD [1-5, 20, 23-25], these findings may be limited in application to other type A AAD patients because of the relatively homogenous population. Thirdly, the control of heart rate was not sufficient in our population because no one achieved less than $60 \mathrm{bpm}$ and only 19 patients were less than 70. Although patients with beta-blockers tended to have a lower heart rate as shown in Table 3, it is difficult to reduce the heart rate after surgical repair due to multiple factors including, inflammation, infection, and atrial fibrillation. Fourthly, class effects and dosages of the each medication were not reviewed in this study. We did not test the effect of the combination of drugs that might have more synergy. Furthermore, there was a lack of information regarding additional medications and compliance. The medications at discharge may have been changed later in the study period. It is acknowledged that the medication list at the time of discharge may not adequately reflect longterm medication usage in the study population. Finally, the choice of antihypertensive drugs was made by the individual treating physicians. Selection bias potentially occurred even after adjusting for the risk factors.

\section{Conclusions}

We did not observe a difference in the long-term mortality or incidence of aortic events in patients after repair of type A AAD, when stratified by heart rate during the acute hospitalization. There are several possible explanations for this observation. It remains unknown whether lower heart rate is important for outcomes. These findings suggest the need for further study in randomized clinical trials.

Acknowledgments All the authors declare that they do not have any financial interest. 
Open Access This article is distributed under the terms of the Creative Commons Attribution License which permits any use, distribution, and reproduction in any medium, provided the original author(s) and the source are credited.

\section{References}

1. Bekkers JA, Bol Raap G, Takkenberg JJ, Bogers AJ (2013) Acute type A aortic dissection: long-term results and reoperations. Eur J Cardiothorac Surg 43(2):389-396

2. Gariboldi V, Grisoli D, Kerbaul F, Giorgi R, Riberi A, Metras D, Mesana TG, Collart F (2007) Long-term outcomes after repaired acute type A aortic dissections. Interact CardioVasc Thorac Surg $6(1): 47-51$

3. Melby SJ, Zierer A, Damiano RJ Jr, Moon MR (2013) Importance of blood pressure control after repair of acute type a aortic dissection: 25-year follow-up in 252 patients. J Clin Hypertens (Greenwich) 15(1):63-68

4. Stevens LM, Madsen JC, Isselbacher EM, Khairy P, MacGillivray TE, Hilgenberg AD, Agnihotri AK (2009) Surgical management and long-term outcomes for acute ascending aortic dissection. J Thorac Cardiovasc Surg 138(6):1349-1357 e1341

5. Tan ME, Morshuis WJ, Dossche KM, Kelder JC, Waanders FG, Schepens MA (2005) Long-term results after 27 years of surgical treatment of acute type a aortic dissection. Ann Thorac Surg 80(2):523-529

6. Shores J, Berger KR, Murphy EA, Pyeritz RE (1994) Progression of aortic dilatation and the benefit of long-term beta-adrenergic blockade in Marfan's syndrome. N Engl J Med 330(19): 1335-1341

7. Genoni M, Paul M, Jenni R, Graves K, Seifert B, Turina M (2001) Chronic beta-blocker therapy improves outcome and reduces treatment costs in chronic type B aortic dissection. Eur J Cardiothorac Surg 19(5):606-610

8. Kodama K, Nishigami K, Sakamoto T, Sawamura T, Hirayama T, Misumi H, Nakao K (2008) Tight heart rate control reduces secondary adverse events in patients with type B acute aortic dissection. Circulation 118(14 Suppl):S167-S170

9. Taguchi E, Nishigami K, Miyamoto S, Sakamoto T, Nakao K (2013) Impact of shear stress and atherosclerosis on entrance-tear formation in patients with acute aortic syndromes. Heart Vessels. doi:10.1007/s00380-013-0328-z

10. Wheat MW Jr, Palmer RF, Bartley TD, Seelman RC (1965) Treatment of dissecting aneurysms of the aorta without surgery. J Thorac Cardiovasc Surg 50:364-373

11. Austen WG, DeSanctis RW (1966) Dissecting aneurysm. Surg Clin North Am 46(3):573-586

12. Tsai TT, Nienaber CA, Eagle KA (2005) Acute aortic syndromes. Circulation 112(24):3802-3813

13. Suzuki T, Isselbacher EM, Nienaber CA, Pyeritz RE, Eagle KA, Tsai TT, Cooper JV, Januzzi JL Jr, Braverman AC, Montgomery DG, Fattori R, Pape L, Harris KM, Booher A, Oh JK, Peterson M, Ramanath VS, Froehlich JB (2012) Type-selective benefits of medications in treatment of acute aortic dissection (from the International Registry of Acute Aortic Dissection [IRAD]). Am J Cardiol 109(1):122-127

14. Zierer A, Voeller RK, Hill KE, Kouchoukos NT, Damiano RJ Jr, Moon MR (2007) Aortic enlargement and late reoperation after repair of acute type A aortic dissection. Ann Thorac Surg 84(2):479-486 (discussion 486-477)

15. Estrera AL, Miller CC 3rd, Safi HJ, Goodrick JS, Keyhani A, Porat EE, Achouh PE, Meada R, Azizzadeh A, Dhareshwar J, Allaham A (2006) Outcomes of medical management of acute type B aortic dissection. Circulation 114(1 Suppl):I384-I389

16. Sakakura K, Kubo N, Ako J, Fujiwara N, Funayama H, Ikeda N, Nakamura T, Sugawara Y, Yasu T, Kawakami M, Momomura S (2009) Determinants of long-term mortality in patients with type B acute aortic dissection. Am J Hypertens 22(4):371-377

17. Delsart P, Beregi JP, Devos P, Haulon S, Midulla M, MounierVehier C (2013) Thrombocytopenia: an early marker of late mortality in type B aortic dissection. Heart Vessels. doi:10.1007/ s00380-013-0354-x

18. Brooke BS, Habashi JP, Judge DP, Patel N, Loeys B, Dietz HC 3rd (2008) Angiotensin II blockade and aortic-root dilation in Marfan's syndrome. N Engl J Med 358(26):2787-2795

19. Mochizuki S, Dahlof B, Shimizu M, Ikewaki K, Yoshikawa M, Taniguchi I, Ohta M, Yamada T, Ogawa K, Kanae K, Kawai M, Seki S, Okazaki F, Taniguchi M, Yoshida S, Tajima N (2007) Valsartan in a Japanese population with hypertension and other cardiovascular disease (Jikei Heart Study): a randomised, openlabel, blinded endpoint morbidity-mortality study. Lancet 369(9571):1431-1439

20. Fattouch K, Sampognaro R, Navarra E, Caruso M, Pisano C, Coppola G, Speziale G, Ruvolo G (2009) Long-term results after repair of type a acute aortic dissection according to false lumen patency. Ann Thorac Surg 88(4):1244-1250

21. Yu HY, Chen YS, Huang SC, Wang SS, Lin FY (2004) Late outcome of patients with aortic dissection: study of a national database. Eur J Cardiothorac Surg 25(5):683-690

22. Dean JC (2002) Management of Marfan syndrome. Heart 88(1):97-103

23. Evangelista A, Salas A, Ribera A, Ferreira-Gonzalez I, Cuellar H, Pineda V, Gonzalez-Alujas T, Bijnens B, Permanyer-Miralda G, Garcia-Dorado D (2012) Long-term outcome of aortic dissection with patent false lumen: predictive role of entry tear size and location. Circulation 125(25):3133-3141

24. Modi A, Vohra HA, Kaarne M, Haw MP, Barlow CW, Ohri SK, Livesey SA, Tsang GM (2011) Long-term outcome following repair of acute type A aortic dissection after previous cardiac surgery. Interact CardioVasc Thorac Surg 13(4):386-391

25. Tsai TT, Evangelista A, Nienaber CA, Trimarchi S, Sechtem U, Fattori R, Myrmel T, Pape L, Cooper JV, Smith DE, Fang J, Isselbacher E, Eagle KA (2006) Long-term survival in patients presenting with type A acute aortic dissection: insights from the International Registry of Acute Aortic Dissection (IRAD). Circulation 114(1 Suppl):I350-I356 